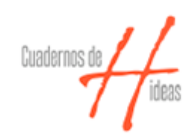

Cuadernos de $\mathrm{H}$ ideas

ISSN: 2313-9048

cuadernosdehideas@perio.unlp.edu.ar

Universidad Nacional de La Plata

Argentina

\title{
Reseña a Smart CitiZens. Ciudades a escala humana
}

\author{
Cardoso, Joaquín \\ Reseña a Smart CitiZens. Ciudades a escala humana \\ Cuadernos de $\mathrm{H}$ ideas, vol. 13, núm. 13, 2019 \\ Universidad Nacional de La Plata, Argentina \\ DOI: https://doi.org/10.24215/23139048e029
}

Esta obra está bajo una Licencia Creative Commons Atribución-NoComercial-Compartirlgual 4.0 Internacional 


\section{Reseña a Smart CitiZens. Ciudades a escala humana}

Review to Smart CitiZens. Cities on a human scale

Joaquin Cardoso

DOI: https://doi.org/10.24215/23139048e029

Facultad de Ciencias Sociales. Universidad de Buenos Aires,

Argentina

joaquin.cardoso@gmail.com

(D) http://orcid.org/0000-0003-0915-0489

Recepción: 15 Julio 2019

Aprobación: 10 Noviembre 2019

Publicación: 19 Diciembre 2019

Gutiérrez-Rubí Antoni. Smart CitiZens. Ciudades a escala humana.

2017. España. Grafiko. 83pp.

Recepción: 15 Julio 2019

Aprobación: 10 Noviembre 2019

Publicación: 19 Diciembre 2019

\section{INTRODUCCIÓN}

Desde las respuestas al paganismo por parte de Agustín en La ciudad de Dios, pasando por los antiguos griegos y la polis, hasta las reflexiones de Lefebvre sobre el derecho a la ciudad, muchos fueron los pensadores que tomaron el tópico urbano como uno de los temas más importantes para pensar la dinámica social general sea precapitalista, sea capitalista.

En este artículo comentamos someramente el último libro Antoni Gutiérrez-Rubí para detectar en él una tendencia que es una constante en sus trabajos, nos referimos al abordaje de problemáticas relacionadas fundamentalmente- con el lenguaje, la tecnología, el modo de vivir urbano y la globalización económica y cultural.

Este asesor político, especialista en medios de comunicación y redes, que ha sido consejero de personajes políticos tan disímiles como Alfredo Pérez Rubalcaba (en un intento de revivir al PSOE de su enésima crisis), Juanma Moreno (del Partido popular andaluz, de matriz conservadora) hasta en estas pampas a la ex presidenta Cristina Fernández de Kirchner y actualmente a Sergio Massa, es asiduo colaborador del Diario El País ${ }^{1}$ y una persona de permanente consulta para cursos internacionales, seminarios e incluso asistencia comunicacional para firmas como Google.

En sus últimos cuatro libros, sin contar uno que se vendió junto al diario anteriormente mencionado ${ }^{2}$, se destaca su continuo interés en mostrar novedades -donde las hay, y donde no las hay también- en lo referido a la concepción del mundo de la política y de la comunicación, de acuerdo a sus planteos distantes con respecto a métodos que considera desfasados o anticuados.

\section{CiUdADES "INTELigentes"}

“(...) ¿cuándo comenzará el pueblo a responder a esta guerra de clases? Uno de los lugares donde podría empezar sería la rápida degradación de la calidad de la vida urbana, como consecuencia de los desahucios, la persistencia de prácticas predadoras en el mercado de la vivienda (...) La crisis es ahora más que nunca una crisis urbana.”

(Harvey, 2013)

Así como la técnica, el lenguaje, la espiritualidad y la filosofía 2.0 pueden nutrir las páginas de un asesor reputado en comunicación política, el discurso "comunitario" al cual se adscribe sirve -como los 
nacionalismos o el deporte- a la fundación discursiva de comunidades virtuales que imaginariamente intentan suspender las desigualdades estructurales que bullen por dentro.

En este caso, "ciudadanía", como en otro momento histórico con García Canclini, la UNESCO o los discursos educativos del Banco Mundial, es el vocablo que se posiciona en el libro Smart citiZens para explicar y añorar una época de democracia horizontal en el marco de las nuevas y tecnificadas ciudades. El peligro del control social a través de la técnica total(2017, p. 29), como tantas veces que hubo crisis profundas, se sustituye contradictoriamente con desplazamientos que colocan el acento ciudadano para dar cuenta de una supuesta otra sociedad: es el caso del foco puesto en la soberanía del sujeto sobre la tecnología y no al revés (p. 72).

En el prólogo, "Mapas del poder" ya anticipa una asimilación entre el esquema cerebral neuronal en red y la metáfora neurocientífica para analizar redes sociales y el modelo rizomático. Luego, esta cartografía posmoderna se ve desarrollada en los posteriores artículos para explicar el papel central de las ciudades, y el desafío que implicaría, siempre de acuerdo a Rubí, poner el foco en lo particular (alcaldías, cercanía con los "ciudadanos") o si dejamos que el sujeto de la gobernabilidad sea el sujeto frío de la técnica controladora. Dice:

Más de la mitad de la población mundial vive en un $2 \%$ del territorio del planeta. El vertiginoso proceso de urbanización es, sin duda alguna, uno de los principales factores de cambio de las sociedades contemporáneas. Las ciudades -y sus alcaldesya pueden ser considerados actores políticos de primer orden (p. 26).

Y luego:

Es un cambio en el fondo pero también en las formas. La comunicación de las ciudades va a poner más acento en los intangibles. Habrá un desplazamiento hacia valores, más cerca de lo cultural, de lo espiritual, de lo vital, de lo cotidiano, de la felicidad (p. 36).

\section{Compendio}

De "la política de las emociones" pasando por el uso de los datos masivos en la vida cotidiana y la configuración de la ciudad en favor de intereses de control social, Gutiérrez Rubí recoloca grandes tópicos de agenda mundial en favor de una perspectiva que, en lo declamativo, favorezca mejorar las relaciones humanas en el mundo globalizado. El punto es que olvida, en su propio desarrollo, las desigualdades sociales que recorren la vida urbana, y elude el lugar predilecto para la circulación del capital (y por eso, para el despojo de grandes capas poblacionales) de la ciudad moderna.

Como anticipó en 1970 Lefebvre, en una introducción que ya es un clásico para abordar la problemática urbana,

Nuestro punto de partida será una hipótesis: la urbanización completa de la sociedad, hipótesis que habrá que defender con argumentos y apoyar con hechos. Ello implica una definición: llamaremos 'sociedad urbana' a aquella que surge de la urbanización completa, hoy todavía virtual, pero pronto realidad (1972: p2)

La sociedad urbana ya no es una potencialidad sino una realidad. Pero, como diría Harvey los materialistas históricos han desestimado la problemática espacial dentro del entramado global del capital, en lo que supone una carencia teórica que no favorece la crítica de la economía política actual ${ }^{3}$. Jameson, a quien ya hemos nombrado anteriormente, en un libro reciente, también trabaja este tópico en términos de capital, sencillamente porque pensar la ciudad carente de este desarrollo contradictorio del capital elude la cuestión más básica: la desigualdad social que ejerce este en su propio desarrollo, y de la cual lo urbano es un elemento necesario y suficiente. Las palabras que usa son las siguientes:

(las grandes ciudades) terminan por excluir de su centro a la siempre creciente población que las han construido (...) lo que más tarde será denominado gentrificación es entonces el equivalente urbano de los desalojos y la despoblación del campo, hasta los barrios obreros de las ciudades tradicionales son vaciados y reconstruidos para inquilinos más ricos (aclaración propia, 2011, p. 154). 
Un estudio sistemático que se referencie en la dialéctica no puede desestimar nociones como las que Gutiérrez Rubí aborda, porque podría enriquecer la cuestión dinámica e histórica del planteo de las redes, el lenguaje y la globalidad de la mercancía en términos de modificaciones del planeamiento urbano, entre otras cuestiones, pero para eso debe partir de la admisión de que vivimos una modificación cultural permanente, siempre con el nudo subrepticio de la explotación social.

Si bien los autores clásicos han legado la posibilidad de pensar críticamente los procesos que tienen la transformación cultural como uno de sus componentes fundamentales, reducir la cuestión a criticar ciertos determinismos (como el tecnológico), suena insuficiente en momentos en que, cualitativamente, la experiencia cultural ha mutado. Esto no transforma al análisis social en ecléctico, sino que con las mejores armas teóricas heredadas se puede abordar dialécticamente un proceso que no comporta sólo novedades de magnitud cuantitativa sino también existenciales.

Un libro como Ciudades rebeldes de David Harvey, que aborda el mismo tema, contempla en términos de intrincados mecanismos de complejidad este desarrollo (y la crisis) del capital y cómo esto afecta la vida urbana y a quienes viven en ella.

En ese sentido, la conclusión a la que llega Rubí en Smart CitiZen, es sintomática de toda una literatura de ciencias sociales que no han hecho más que seguir los preceptos temáticos de las grandes unidades institucionales (financieras o educativas): la diatriba entre una ciudad para la tecnología o una ciudad para los ciudadanos. La apelación a la ciudadanía abstrae esta terminología -otrora revolucionaria, otrora liberalpara dotarla de cierta ambigüedad que pueda ser disputada de acuerdo a las necesidades e intereses sociales. Por la actividad frecuente de este autor en asesorías políticas y de mercado, podemos deducir quién orienta este corpus.

\section{ReFERENCIAS}

Entrevista a David Harvey (2009-2010). Cuadernos críticos de comunicación y cultura, (5).

Gutiérrez-Rubí, A. (2015). La politica en tiempos de Whatsapp. Recuperado de https://www.gutierrez-rubi.es/la-pol itica-en-tiempos-de-whatsapp/

Gutiérrez-Rubí, A. (2017). SmartCitizens. Ciudades a escala humana. Recuperado de https://www.gutierrez-rubi.es /2017/11/13/smart-citizens-ciudades-escala-humana/

Harvey, D. (2013). Ciudades rebeldes. Del derecho de la ciudad a la revolución urbana. Madrid, España: Akal.

Jameson, F. (2011). Representar El Capital. Ciudad Autónoma de Buenos Aires, Argentina: Fondo de Cultura Económica.

Lefebvre, H. (1972). La revolución urbana. Madrid, España: Alianza.

\section{Notas}

1 El vicejefe de redacción de El País de España es, precisamente, Rubalcaba, su asesorado.

2 Nos referimos a La politica en tiempos de whatsapp(Diario El País, 2015).

3 En una entrevista de 2010, dice "Los marxistas no son buenos geógrafos, por ejemplo, son muy débiles para entender las diferencias geográficas y los espacios de producción” (Cuadernos Críticos de Comunicación y Cultura, Nro5, Dic 2009 - Marzo 2010).

\section{BY-NC-SA}

